\section{Geochemical characterisation of Otumba obsidian sub-sources (Central Mexico) by inductively coupled plasma mass spectrometry and density-based spatial clustering of applications with noise statistical analysis}

\author{
Denisse Argote-Espino, ${ }^{1}$ Jesús Solé, ${ }^{2}$ \\ Pedro López-García, ${ }^{1}$ Osvaldo Sterpone ${ }^{1}$ \\ 'Instituto Nacional de Antropología e \\ Historia, Mexico City; ${ }^{2}$ Instituto de \\ Geología, Universidad Nacional \\ Autónoma de México, Mexico City, \\ Mexico
}

\section{Abstract}

Several obsidian sources that were significant to the lithic industry all over Mesoamerica are contained in the Central Mexico highlands. Many archaeological investigations have suggested that the economical and political expansion of important Mesoamerican cultures was related to the control of obsidian sources and its commercial routes. One of these sources was Otumba, located west of the Teotihuacan Valley. This region has several sub-sources, some of which have been studied in more detail than others. The most studied subsource is the one located on Soltepec Hill, but other related sub-sources within Otumba region that have not been studied include the Ixtete, Pacheco, Malpais and Tepayo domes. We have analysed samples from these four sub-sources with inductively coupled plasma mass spectrometry (ICP-MS) method to determine their chemical similarities and differences and classify them. The individual correlation of different archaeological artifacts with each sub-source could tell us about exploitation preferences of the diverse cultures controlling the source or even sequence in time of its utilisation.

\section{Introduction}

Nowadays, artifact chemical analyses play an important role in provenance studies. Obsidian is a good archaeological material for this kind of research when compared to organic or ceramics samples because the internal composition of an obsidian flow is usually very homogeneous and exhibits little variability, but differences between volcanic regions are large. Therefore, the use of a high precision chemical technique can lead to the identification of sources with a high degree of certainty. Multi-elemental analysis applied to obsidian archaeological samples can discover a distinctive trend or pattern traceable to their natural source. Several studies on this topic have already been published and the reader is encouraged to follow research undertaken by Carballo, Cobean, Glascock, Healan, Neff, Neivens, Smith, Spence, Vogt, Weigand (e.g. Carballo et al., 2007; Cobean, 2002; Glascock et al., 1998; Healan, 1997; Neivens et al., 1989; Nelson et al., 1995; Smith et al., 2007).

Finding the link between quarry production and obsidian products in a regional exchange context requires accurate characterisation of lithic artifacts. A single volcanic region can include several obsidian flows showing different optical properties and that could present different chemical patterns. The individual correlation of different archaeological artifacts with each sub-source could tell us about exploitation preferences of the diverse cultures controlling the source or even sequence in time of its utilisation. Sub-source characterisation can be used to trace artifacts back to a specific quarry location (Braswell et al., 1994, 2004). It is worthwhile to spend time and effort ascribing obsidian to chemically distinct subsources that are available in the same spatial location (Eerkens and Rosenthal, 2004). The presence of several obsidian flows are known in Sierra de Pachuca and Otumba volcanic regions, giving us the possibility of been able to discriminate their individual chemical patterns. A powerful analytical technique [inductively coupled plasma mass spectrometry (ICPMS)] was applied in order to define the key trace-elements capable of discriminate between the different sub-sources.

\section{Otumba volcanic complex}

The Otumba Volcanic Complex is located in the central part of the Trans-Mexican Volcanic Belt, between the state limits of Estado de Mexico, Hidalgo and Tlaxcala. It is the closest obsidian natural deposit to the city of Teotihuacan and was intensively worked in Teotihuacan's workshops in the first centuries AD (Spence and Parsons, 2007; Clark, 1989). Previous tectonic studies mention that the Otumba region was affected by two principal fault systems (Figure 1). The first is a NW-SE fault system that Mooser (1968) associates with the Chapala-Acambay fault system. The northern part of the field area is represented by a complex of rhyolite domes and scoria cones aligned with Cerro Gordo Complex; this alignment continues as far as Tizayuca, Hidalgo, and was designated by García-Palomo et al. (2002) as Cerro Gordo-Las Navajas horst. The second is a NE-SW fault system designated by Mooser (1968) as the Soltepec fracture zone. Its principal geological structure consists
Correspondence: Denisse Argote-Espino, Instituto Nacional de Antropologia e Historia, Cordoba 45, Cuauhtemoc 06700, Mexico City, Mexico. Tel./Fax: +55.5675.0029

E-mail: efenfi@gmail.com

Key words: obsidian, Otumba, ICP-MS, DBSCAN.

Citation: Argote-Espino D, Solé J, López-García P, Sterpone 0, 2013. Geochemical characterisation of Otumba obsidian sub-sources (Central Mexico) by inductively coupled plasma mass spectrometry and density-based spatial clustering of applications with noise statistical analysis. In: RH Tykot (ed.), Proceedings of the $38^{\text {th }}$ International Symposium on Archaeometry - May $10^{\text {th }}$-14 $4^{\text {th }} 2010$, Tampa, Florida. Open Journal of Archaeometry 1:e18.

Acknowledgments: this research has been supported by PAPIIT-UNAM Mexico project No. IN118809. Authors thank Patricia Girón, Elena Lounejeva and Juan Pablo Bernal, from XRF and ICP-MS labs, for the great and patient assistance in the instrumental analysis. Authors also thank Gustavo Tolson, José Luis Arce and the anonymous reviewers for their enlightening comments.

Presented at the $38^{\text {th }}$ International Symposium on Archaeometry - May $10^{\text {th }}-14^{\text {th }} 2010$, Tampa, Florida.

This work is licensed under a Creative Commons Attribution 3.0 License (by-nc 3.0).

(C) Copyright D. Argote-Espino et al., 2013

Licensee PAGEPress, Italy

Open Journal of Archaeometry 2013; 1:e18

doi:10.4081/arc.2013.e18

of a normal fault system with monogenetic volcanic cones, several lava flows and obsidian domes in the central part of the area (Soltepec Range).

Soltepec obsidian source (within Otumba volcanic complex) is a rhyolite calc-alkaline volcanic center located East of the Teotihucan Valley. It covers an approximate area of $13 \mathrm{~km}^{2}$ and consists of a sequence of obsidian flows intercalated with rhyolite microcrystalline rock associated with domes. These eruptive centers are found along the Soltepec Range and are related to the emplacement of a group of rhyolitic domes from the early Pleistocene and possibly earliest Holocene period (according to $\mathrm{K}-\mathrm{Ar}$ and Ar-Ar dating) having a preferential NW-SE direction. As said before, the exploitation of this geological deposit is associated with Teotihuacan city since its first phases. The extraction of obsidian in this location was easy because the obsidian blocks within the flow carapace were supported by a very weak matrix. Its principal obsidian mines were distributed along the Soltepec dome, next to Cuello volcano and the Tepayo dome. Soltepec 
hill is a volcanic structure composed of a series of domes. There are two places within where a larger outcrop of the natural obsidian flow can be observed, as can be the presence of some pre-Hispanic workshops: el Salto de las Peñas and Estetes Gully (this term comes for the word Ixtetes that means obsidian in Nahuatl). There are also two gullies that cut part of the obsidian flow: El Muerto and Las Navajas. Buenavista Volcano is a scoria cone that covers the obsidian flow of the Soltepec Complex.

Around it are abundant cinder and scoria deposits stratified with abundant dark and brown obsidian (called Meca) xenoliths.

Otumba's obsidian complex includes other near obsidian sources some of which have been reported in archaeological literature, such as Malpais (Cobean, 2002; Mora, 1981). Although occasionally mentioned (Granados et al., 1991; Spence and Parsons, 1967), they have not been reported as sources properly. That is the case of Tepayo and Ixtepec domes. The Ixtepec (Obsidian hill) source is located 3 $\mathrm{km}$ NE of Otumba's main source (Soltepec dome). The nearest towns are Jaltepec and Hacienda de Campero, between Mexico and Hidalgo State limits. At the gullies known as La Rinconada and los Ocotes are several preHispanic mines. Tepayo dome is located at 5 $\mathrm{km} \mathrm{N}$ of Soltepec dome, near Ixtepec dome and at a side of Hacienda de Campero. Hernandez (Hernandez Javier, 2007) mentions that the obsidian can be found in the NW slope of Tepayo's main dome, and that there are no archaeological researches related to this place. Malpais source is located near Hacienda de Malpais and consists of an obsidian dome partially covered by lava flows from Cerro Cuello. Another dome is located between Ixtepec Hill and Malpais dome called Pacheco hill; this hill also has an exposed obsidian flow.

These other sources within Otumba's volcanic complex have not yet been geochemically studied, little is known about the extraction of raw material from these sub-sources and the importance they had in pre-Hispanic economy. So, in this work we intend to explore the possibility of chemically differentiating each subsource. In previous experiments, XRF sequential analysis of major and heavy trace elements proved inconclusive to this particular issue, so ICP-MS was also applied to samples from this natural source region in order to obtain data of higher resolution.

\section{Materials and Methods}

\section{Instrumentation}

The induced couple plasma (ICP) mass spectrometry was developed in the 80's decade and combines the ICP technology with the accuracy and low limit detection of a mass spectrometer, which makes it easier to introduce samples plus provides a faster analysis (Jarvis et al., 1996). This instrument is capable of a trace multi-elemental analysis, usually to a level of parts per trillion (ppt). The ICP was built based on the same physical principles used in atomic emission spectrometry. Samples are decomposed in charged atomic elements within high-temperature argon plasma and analysed in accordance with the mass/charge ratio (Potts, 1995). Accuracy may be determined by analizing reference materials with certified values and comparing the analytical results to the certified values (use of calibration standards). It should be kept in mind that accuracy depends not only on instrument performance but also on the laboratory techniques of the analyst (Rollinson, 1993). Since ICP-MS is not an absolute analytical technique, standard samples and a blank solution must be analysed. Its detection limits are lower than other instrumental methods, generally in the order of $1 \mathrm{ppb}$ (parts per billion) for light elements and 50 ppt (parts per trillion) for heavy elements.

The disadvantage of this method is that the destruction of the sample is needed if a laser ablation instrument (LA-ICP-MS) is not available (Gratuze, 1999; Speakman and Neff, 2005). The advantage of the laser ablation system is that it only needs to extract a minimal sample from the piece (about $10 \mu \mathrm{m}$ diameter spot), sending it directly to the ICP, but the detection limit decreases to parts per million, which is significantly lower compared to the usual ICP procedure (Eastwood et al., 1998). Some other benefits of using ICP-MS are that its cost per sample is much lower than instrumental neutron activation analysis (INAA) analysis and that a sample size of one to eight for ICP-MS is comparable to the analysis of over 30 quarry samples with INAA (2007). Although Carballo et al. (2007) used laser ablation for ICP-MS sample introduction, it is widely known that regular ICP with sample digestion has lower detection limits, producing more accurate results. Therefore, the conclu- sions at Carballo et al. (2007) regarding the sample size necessary to obtain adequate results (one to eight) is also applicable in our study.

\section{Statistical processing of composi- tional data}

Data mining is a new variant of data analysis which extracts tools and techniques from different areas including pattern recognition, statistics and data base systems. The objective of data mining is to analyse large complex data sets although it can be also used for small data sets making some modifications to the algorithm conditions. It detects underlying relationships between attributes in a data set, dis-

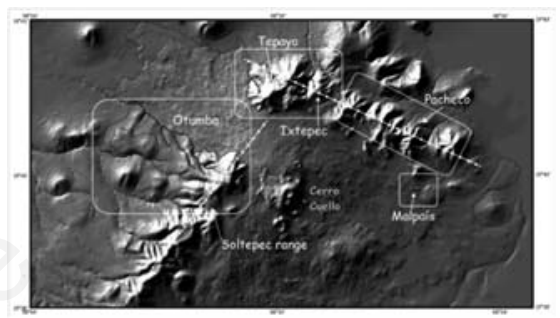

Figure 1. Otumba volcanic complex geomorphologic map, modified from Hernandez (2007). The Chapala-Acambay fault system runs NW-SE and the Soltepec fracture zone runs NE-SW.

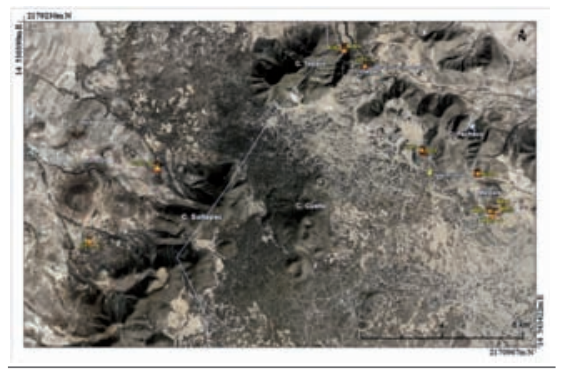

Figure 2. Satellite image of Otumba region. The location of the collected samples is marked in the image.

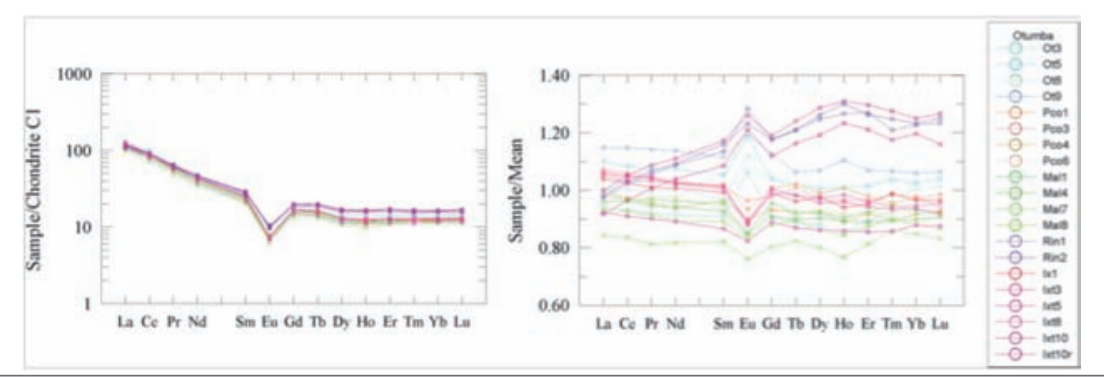

Figure 3. Rare earth elements concentrations for Otumba samples normalised to chondrite (left) to corroborate the geochemical consistency of the results, and normalised to the mean value of the samples (right) to maximise the differences between them. 
covering similar patterns or performing classifications or predictions (Rushing et al., 2005). One of these new methods is the density based spatial clustering of applications with noise (DBSCAN) algorithm. It was originally developed by Martin Ester, Hans-Peter Kriegel, Jörg Sander and Xiaowei Xu (Ester et al., 2006) and operates under the principle of density (produced by data partition in which the group number is automatically determined by the algorithm). DBSCAN can discriminate high density from low density regions, can detect arbitrarily shaped clusters, determine nearby clusters and identify points not belonging to any group (also known as noise). One advantage of DBSCAN is its flexibility. First of all, it does not require that the user know the number of clusters present in the data before the analysis, an indispensable requirement for non-hierarchical clustering techniques. Second, it can detect clusters locked in another cluster, even when they are not connected.

The clusters are considered as regions in an $n$-dimensional space, where the clusters are composed of high point densities separated by regions of low point densities. A density is defined by $m$ number of points within a specific radius. DBSCAN starts with an arbitrary non-visited point selected from the data mass. The neighborhood of this particular point is determined by a radial distance called epsilon $(\varepsilon)$. If the number of points contained within this distance are enough (more than or equal to the minimum number of points defined by the user) a cluster is formed; if not, the point is identified as noise. For the minimum number of points Ester et al. (2006) suggest a value of 4 MinPts. They have found in experimental tests with real and synthetic data that the DBSCAN algorithm did not present variations in the analysis of different data bases when using MinPts=4 as a constant value.

Ester et al. (2006) consider that DBSCAN is more effective in the search of clusters with arbitrary shapes than the well known CLARANS algorithm, showing a superior performance by a factor of $100 \%$. Due to all the reasons exposed above, we choose this method

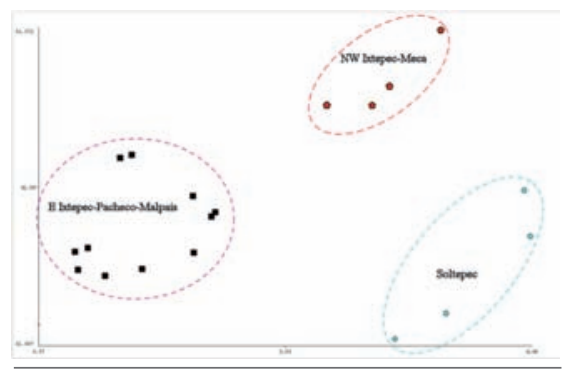

Figure 4. Classification of Otumba samples with density-based spatial clustering of applications with noise analysis. was chosen to analyse and classify the compositional data of our obsidian samples.

\section{Results and Discussion}

Based on Carballo et al. (2007), we used a total of 19 samples from Otumba's region: 4 from each potential sub-source (Soltepec, Ixtepec, Pacheco and Malpais domes), 2 Meca specimens found in the Rinconada gully and one duplicated sample for quality and precision purposes. The collection points can be seen in Figure 2. We tried to cover a wide area around the regions of interest in order to secure variability of the data. To avoid fieldwork errors, all the samples were collected directly from the rock carapace exposed in the outcrop areas; loose pieces on the ground were never taken.

All samples were analysed in the Geology Institute (UNAM) using an AGILENT 7500ce ICP-MS instrument. We performed acid digestion on the samples, according to the analytical procedures modified from Eggins et al. (1997). For quality purposes, the samples were analysed at the same time with 4 reference materials (BHVO-1, RGM-1, GSR-2 y SD0-1) using the values published by Govindaraju (1994); also, a reference material (andesite IGLa-1) developed in the Ultra Pure Chemistry Lab of our Institute (Lozano Santa-Cruz and Bernal, 2005) was used in order to evaluate the precision and accuracy of the results.

Finally, to corroborate the geochemical consistency of the results, a graphic of the rare earth elements (REE) concentrations normalised to chondrite was created using the values reported by McDonough and Sun (1995). As can be seen in Figure 3 (left), the pattern exposed in the chondrite normalisation is very similar among samples. To enhance the differences between samples of the same region, we also normalised the data using the lower values of the REE concentrations (Figure 3, right). The differences between the samples' REE patterns was more pronounced presenting three presumably separate groups.

The analytical results are shown in Supplementary Table 1. All elemental data was statistically processed and classified with DBSCAN algorithm using the methodology described earlier in this article. WEKA software (Hall et al., 2009) was used for this purpose. In Otumba's volcanic region the resulting classification of the data (Figure 4) shows three groups: one for the Soltepec area, one for the East Ixtepec-Pacheco-Malpais range and a third one containing the Meca obsidian with one specimen of gray obsidian that we first assume corresponded to NW Ixtepec dome. Meca is brownish spotted obsidian that owes its distinctive color to the rapid oxidation of iron in the outer part of the obsidian flow just before its solidification (Winter, 2001). Although loosely Meca obsidian samples were collected from La Rinconada gully that divides Tepayo and Ixtepec hills, the gray obsidian sample related to it was taken directly from the rock carapace located at the conjunction of the Tepayo and Ixtepec flows, in the northwestern flank of Ixtepec hill. This sample (called Ixt10), was measured twice to corroborate the results, giving the same values each time. Although Hernandez (2007) describes the presence of an obsidian flow in the northwestern flank of Tepayo hill, the team was unable to find remains of an obsidian flow in this area. Subsequently, it is presumed that Meca obsidian proceeds from an earlier obsidian flow of the Ixtepec dome and not from the Tepayo dome, unless Tepayo hill has a deeply buried obsidian flow that cannot be observed from surface and that can only be hit by a profound excavation system (possible shaft mines).

\section{Conclusions}

Obsidian was one of the principal components in the economical and cultural structures of pre-Columbian Mesoamerican civilizations. Worldwide studies have shown the great potential of analytical methods in the geochemical characterisation of obsidian sources and the identification of provenance of archaeological artifacts in order to determine cultural influences and antique commercial routes. Furthermore, a profound chemical characterisation of the sources is useful in order to divide them into different smaller regions (sub-sources). By this means, the exploitation sequences of the geological deposits can be more accurately. As Neivens et al. (1989) wrote: micro-sourcing offers the archaeologist a tool for looking beyond the trade routes and into the processes of economic and social order.

Although less expensive methods such as XRF have been proven efficient in the identification of regional obsidian sources, ICP-MS has been confirmed as a powerful method in the chemical high-precision characterisation of obsidian sub-sources. For example, in the Otumba volcanic complex, although the region is more chemically similar to other obsidian source zones, sub-sources could be determined using this modern analytical technique. The lower detection limits of this instrument permitted the determination of more slight variations in the elemental composition of the samples that could not be observed with other methods, allowing the partition of the geological deposit in smaller regions. Furthermore, DBSCAN statistical analysis improved the accuracy of the results and to produce a less biased classification, exposing underlying 
relationships between variables not visible in pure qualitative graphical methods.

\section{References}

Braswell GE, Andrews EW, Glascock MD, 1994. The obsidian artifacts of Quelepa, El Salvador. Ancient Mesoam 5:173-92.

Carballo DM, Carballo J, Neff H, 2007. Formative and classic period obsidian procurement in Central Mexico: a compositional study using laser ablation-inductively coupled plasma-mass spectrometry. Lat Am Antiq 18:27-43.

Clark J, 1989. The distribution of obsidian. In: V. Voorheis (ed.) Ancient trade and tribute: economies of the Soconusco region of Mesoamerica. University of Utah Press, Salt Lake City, pp 268-84.

Cobean RH, 2007. A world of obsidian: the mining and trade of a volcanic glass in ancient Mexico. INAH and Pittsburgh University ed., Mexico.

Eastwood WJ, Pearce JG, Westgate JA, Perkins WT, 1998. Recognition of Santorini (Minoan) tephra in lake sediments from Gölhisar Gölü, Southwest Turkey by laser ablation ICP-MS. J Archaeol Sci 25:677-87.

Eerkens JW, Rosenthal JS, 2004. Are obsidian subsources meaningful units of analysis?: temporal and spatial patterning of subsources in the Coso Volcanic Field, southeastern California. J Archaeol Sci 31:21-9.

Eggins SM, Woodhead JD, Kinsley LPJ, Mortimer GE, Sylvester P, McCulloch MT, Hergt JM, Handler MR, 1997. A simple method for the precise determination of $>=40$ trace elements in geological samples by ICPMS using enriched isotope internal standardization. Chem Geol 134:311-26.

Ester M, Kriegel HP, Sander J, Xu X, 1996. A density-based algorithm for discovering clusters in large spatial databases with noise. In: II International Conference on Knowledge Discovery and Data Mining, pp 226-31.

García-Palomo A, Macías JL, Tolson G, Valdez G, Mora JC, 2002. Volcanic stratigraphy and geological evolution of the Apan region, east-central sector of the Trans-
Mexican Volcanic Belt. Geofís Int 41:13350.

Glascock M, Braswell GE, Cobean R, 1998. A systematic approach to obsidian source characterization. In: S. Shackley (ed.) Archaeological obsidian studies. Plenum Press, New York, pp 15-66.

Glascock MD, Speakman RJ, Neff H, 2007. Archaeometry at the University of Missouri research reactor and the provenance of obsidian artifacts in North America. Archaeometry 49:343-57.

Govindaraju K, 1994. Compilation of working values and sample description for 383 standard reference materials. Geostandard Newslett 18;331.

Granados VD, Pastrana CA, Sánchez HR, Martínez IR, 1991. [Datos geoarqueológicos del yacimiento de obsidiana de Otumba, México]. [Article in Spanish]. Expres Antropol 2:31-9.

Gratuze B, 1999. Obsidian characterization by laser ablation ICP-MS and its application to prehistoric trade in the Mediterranean and the near East: sources and distribution of obsidian within the Aegean and Anatolia. J Archaeol Sci 26:869-81.

Hall M, Frank E, Holmes G, Pfahringer B, Reutemann P, Witten IH, 2009. The WEKA data mining software: an update. SIGKDD Explor 11:10-8.

Healan DC, 1997. Prehispanic quarrying in the Ucareo-Zinapécuaro obsidian source area. Ancient Mesoam 8:77-100.

Hernandez Javier I, 2007. [Geología y geomorfología volcánica de la región de los yacimientos de obsidiana de Otumba en el sector Norte de la sierra nevada de México]. [MA thesis in Spanish]. Facultad de Filosofía y Letras, Colegio de Geografía, UNAM ed., México.

Jarvis KE, Gray AL, Houk RS, 1996. Handbook of inductively coupled plasma mass spectrometry. Blackie Academic \& Professional, UK.

Lozano Santa-Cruz R, Bernal JP, 2005. Characterization of a new set of eight geochemical reference materials for XRF major and trace element analysis. Rev Mex Cienc Geol 22:329-44.

McDonough WF, Sun SS, 1995. The composition of the earth. Chem Geol 120:223-53.

Mooser F, 1968. [Geología, naturaleza y desar- rollo del Valle de Teotihuacan]. In: J.L. Lorenzo (ed.) [Materiales para la arqueología de Teotihuacan]. [Book in Spanish]. INAH, México, pp 29-37.

Mora R, 1981. [Yacimientos y talleres de obsidiana en el sureste del estado de Hidalgo]. In: M. Gaxiola (ed.) [Yacimientos y talleres prehispánicos de obsidiana del estado de Hidalgo]. [Book in Spanish]. INAH, Mexico, pp 21-38.

Neivens M, Harbottle G, Kimberlin K, 1989. Some geochemical characteristics of the Pachuca obsidian region: a strategy for interpreting artifact groups. [Chapter in English]. In: M. Gaxiola, J.E. Clark (eds.) [La obsidiana en Mesoamérica]. [Book in Spanish]. INAH, Mexico, pp 51-58.

Nelson FW, Healan DM, 1995. Obsidians from the Ucareo and Zinapecuaro areas, Michoacan, Mexico. Geological Society of America ed., Boulder, C0, USA.

Potts PJ, 1995. A handbook of silicate rock analysis. Blackie Academic and professional, UK.

Rollinson H, 1993. Using geochemical data: evaluation, presentation, interpretation. Pearson-Prentice Hall, UK.

Rushing J, Ramachandran R, Nair U, Graves S, Welch R, Lin H, 2005. ADaM: a data mining toolkit for scientists and engineers. Comput Geosci 30:607-18.

Smith ME, Burke A, Hare TS, Glascock MD, 2007. Sources of imported obsidian at Postclassic sites in the Yautepec valley, Morelos: a characterization using XRF and INAA. Lat Am Antiq 18:429-50.

Speakman RJ, Neff H, 2005. Laser ablation ICP-MS in archaeological research. University of New Mexico Press, Albuquerque.

Spence MW, Kimberlin J, Harbottle G, 1984. State-controlled procurement and the obsidian workshops at Teotihuán, Mexico. In: J.E. Ericson and B.A. Purdy (eds.) Prehistoric quarries and lithic production. Cambridge University Press, Cambridge, pp 97-105.

Spence M, Parsons J, 1967. Prehispanic obsidian mines in southern Hidalgo. Am Antiquity 32:542-3.

Winter JD, 2001. An introduction to igneous and metamorphic petrology. Prentice-Hall, New Jersey. 